\title{
Familiarization: Fostering Creative Problem Solving in Engineering Design Education
}

\author{
D.J. Caswell, C.R. Johnston, E. Baraniecke, D. Douglas, M. Eggermont \\ Department of Mechanical and Manufacturing Engineering \\ University of Calgary \\ Calgary, Alberta, Canada \\ djcaswel@ucalgary.ca
}

\begin{abstract}
Developing the skills of creative problem solving in undergraduate engineering education is a significant challenge in the typically analytical engineering training program. The problem lies in the fact that the skills of design and creative problem solving are primarily skills of synthesis rather than analysis. Design instructors at the University of Calgary have developed an approach to design that fosters the development of synthesis skills. This paper develops Familiarization as one component of the approach necessary for creative thinking and provides a description of the classroom requirements for developing the concept.
\end{abstract}

\section{Introduction}

In recent years, the response of North American engineering schools to the Abet and CEAB directive to provide real world, team oriented, open ended design experiences to undergraduate engineering students has focused on the senior year capstone design course. Design work in the final year of the undergraduate program provides an opportunity for students to apply their accumulated engineering knowledge to real world environments. The downside of this practice has been the difficulty in fostering a design mindset at the end of a four year, primarily analytical engineering program. It would be better to develop design skills from the very beginning of undergraduate training. However, the traditional engineering design process assumes experience and familiarity with a wide range of engineering methods and topics, so it is generally reserved for the senior year.

Instructors at the University of Calgary have developed an approach to the design process that addresses these problems and is tailored to the first year engineering student. The approach has also shown promise in professional design work. We refer to the approach as the "Design Trinity" of Familiarization, Functionality and Testing [5]. The design trinity evolved from an earlier exploration and development of a familiarization approach to design [2]. The original goal was to document successful design approaches that were not part of traditional engineering design methodology.

The design trinity is intended to engage novice designers in a way that develops rigor in design work even though they do not have well developed analytical tools or engineering knowledge at their disposal. It is intended to occupy a mid-point between the "man-on-thestreet" approach (an endless cycle of build/fail) with which students generally enter the program, and the highly sophisticated use of successful design methodology which requires years of training. The success of the design trinity lies in its emphasis on action (familiarization, functionality and testing) rather than the documentation of actions already taken in (problem statement, conceptual design, detailed design).

Within the design trinity, we define familiarization as multi-disciplinary communicative action. It allows an engineer to discover how others think about any particular design problem. Functionality isolates what the design must do (rather than what it will look like) and testing provides a proving ground for the evolution of the design.

Familiarization is the focus of this paper. Its value stems from the recognition that every discipline has its own approach to design and most, if not all, share the view that good design seeks to integrate the human experience [16]. Familiarization promotes the humanistic nature of design through the creation of a design environment that values multi-disciplinary input. We will explain our view of familiarization as a pathway to creative problem solving through a critique of the traditional design process followed by an explanation of the roots and utility of the concept. Finally, classroom activities for developing familiarization are discussed

\section{The Problem with the Traditional, Rational Approach to Engineering Design}

At issue in the traditional approach to engineering design is the lack of a suitable response to the fact that the skills of the designer lie more in synthesis (bringing 
together different points of view) than in analysis, yet the training of the engineer is primarily in the area of analysis. [5]. In fact Khisty [8] identifies the biggest problem today in planning and design to be the dominance of technical rationality to the exclusion of communicative action.

In engineering, we experience the problem of the dominance of technical rationality as the chronically unsuccessful "over-the-wall" problem encountered even in professional engineering design projects. The over-thewall problem occurs when an engineer solves any given problem in isolation and according to his/her own, often limited, understanding of the problem. Having completed the design based on a uni-disciplinary point of view, the work is passed along (over the wall) to the next department (eg, manufacturing). Due to the lack of effective communication amongst those involved in the design, critical problems crop up as subsequent participants discover problems with the design when viewed from their own uni-disciplinary perspective. Too often the end result is time, money and market position lost in a spiral of design and redesign as the work is sent back and forth along the line to fix each newly discovered design problem. However, each participant in the development of the design has acted rationally according his/her own technical expertise. Each has faithfully followed the guidelines of technical rationality.

Technical rationality claims that all problems, design or otherwise, can be reduced to a set of fundamental components. Once the components of the problem have been identified, the solution can proceed in an orderly fashion through the solution of one component after another. Adherents to technical rationality believe the path to successful design is simply a matter of working through the constraints dictated by the problem itself. Since there are a finite number of design paths, arguments for or against a particular design are settled by determining which approach provides the best quantitative response to each constraint.

In addition, technical rationality assumes that all information is available; therefore objective and logical steps can be taken to reach an optimal solution. In engineering education, this kind of problem solving approach is presented as a universal methodology. A similar methodology for design is described by Whetten [7] as defining the problem, generating and evaluating alternative solutions and following up on the implementation of the best solution.

However, this universal methodology for the teaching and learning of engineers has been built around "tame" problems and problem solving rather than the creative solution of open-ended or "wicked" problems. Tame problems is a term coined by W.J. Rittel in his design lectures at the University of California, Berkeley [13]. In Rittel's view, math and science problems, which are comprised of clear, theoretically based textbook problems centered around formulaic manipulation, are "tame" problems because they rely on well traveled solution paths that always end up with the same answer. Design problems, however, Rittel describes as "wicked" problems because there is no identifiable solution path or any concept of what the answer might be. In addition, adequate information for analysis is unavailable, incomplete or incorrect. The designer is regularly forced to make decisions based on judgment and experience. Since there is no " right" answer, the solution to a design problem is the best one given the circumstances. Most often, the wickedness of real world design problems does not yield to a universally applied methodology.

As a result, technical rationality has failed to advance the development of engineering design and perhaps the development of design in general. Even in architecture, for example, "most architectural educators think their task is to teach students how to design architecture according to conventionally formal mechanism" [6]. The assumption has been, as it is in the rational and analytical classroom, that correct design theory will yield correct design practice. However, according to Snodgrass [15] the assumption fails in the design classroom. In fact, arming the designer with an abundance of expert and/or scientific knowledge about the subject or about the "correct" design process may actually impede creative thinking [17]. Subject experts are aware of successful procedures and orient their thinking within that particular framework. As a result, the accumulation of objective, factual information moves the designer farther away from a creative solution to the problem.

Technical rationality tends to be the default mode for students when presented with an open-ended design problem. Unfortunately, for the student and for the professional, continued adherence to the set procedures of technical rationality to the exclusion of a more integrative approach to design can only result in the continued creation of inferior designs and products [10].

As an alternative, we propose the concept of familiarization as a vehicle to promote a more integrative approach to design through the exploitation of communicative action.

\section{Familiarization as Communicative Action}

Familiarization, which we define as multidisciplinary communicative action requires that the designer engage in discourse (listening to and collecting stories, points of view and experiences from a wide variety of stakeholders). Exposure to different modes of information expands the solution space beyond simply addressing quantitative constraints [2]. In the familiarization phase, the engineer is not interested in finding a solution, only in gathering information.

For the technical rationalist, this phase is often neglected, perhaps because it seems only to add unnecessary complications. Instead, the rationalist designer quickly adopts and solves an uninformed version 
of the problem. Inevitably he/she then becomes mired in redesign at the end of the project when design changes are difficult and costly to implement.

The goal of familiarization, with its focus on discourse and communication, is to allow the designer to assemble enough outside knowledge to form a basis for synthesis. Provided with an adequate supply of different viewpoints, the designer's understanding of the core problem emerges indirectly. And, as time goes on, the well known stages of successful design will be realized, although not through a simple step by step process. However, the end result of a familiarization approach is more likely to be a design solution that is robust and efficient requiring a minimum of redesign.

In our view, engineering design can and should be something more than an analytical, rational process. Of course, we cannot ignore the importance of rationality, analysis and process. Empirical and rational scientific methodology is the guiding principle of the age. However, the act of creative design is the driving force behind advancement [10]. And, the act of creative design is entirely human, but not entirely rational. Rittel [13] describes the act of design as the telling of a story. Through familiarization, successful design grows out of the creation of a forum for an integration or synthesis of many stories or ways of knowing about the world. Without communicative action, this crucial synthesis cannot take place.

\section{Design, Problem Solving and Creative Thinking}

While analytical problem solving is directed at the solution of tame problems and design involves the solving of wicked problems, the two are so closely tied that designing may be considered a special case of problem solving [3]. Whereas analytical problem solving involves the manipulation of known formulaic procedures, the wickedness or inconvenient reality of design problems leads the designer to pursue alternative approaches to solve a problem. Usually this involves some degree of creativity in addition to analytical procedure. Poincare [11] proposed a "creative" or alternate approach to problem solving:

1. First Insight: The recognition of the problem and the conscious commitment to solving it.

2. Preparation: The development of an idea for solving the problem and a conscious attempt at a solution.

3. Incubation: No conscious effort at finding a solution.

4. Illumination: A sudden emergence of an idea.

5. Verification: Conscious development of the idea into a solution.

The above approach describes a sequence of phases based on observation of how what may be considered creative solutions are derived. Realistically, there are no methods or techniques that can be used to solve a problem creatively. If there were prescriptive creativity techniques, they would no longer be creative but rather procedures. However, neither does Poincare's approach guide the novice to activities leading to creative problem solving. Generating the activities that lead to creative thinking is the role of the design trinity in general and familiarization in particular.

Familiarization is much more than simply gathering expert information. As mentioned, an overabundance of scientific or factual information can be detrimental to creative thinking. Instead, the act of familiarization creates an environment in which the rational or scientific approach is enhanced by the assembly of a wide range of unique, multi-disciplinary and personal perspectives unfiltered by the scientific perspective and its critical public testing of what is taken as knowledge.

Familiarization creates an alternative worldview in which people are seen as "co-creating their reality through participation" [12]. That is, through the sharing of their "experience, their imagination and intuition, their thinking and their action" [12], participants become involved in the construction of new and interdisciplinary knowledge [14].

Through familiarization, not only does the designer benefit from the accumulation of wide ranging and unique knowledge about the design, but the act of engaging in familiarization places the designer firmly on the pathway to creative thinking.

\section{Creative Thinking and Familiarization}

Creative thinking is not common. It involves innovation, originality and the ability to think on a unique level. Everyone has the potential and ability to develop creative expression; the majority of the population, however, tends to utilize well established methods and practices that are common in every day life, thus stifling creativity. Since very few individuals truly function in less well established modes of thought, creative people are rare. However, the practice of familiarization places the designer in a situation where he/she is almost unwittingly led to think creatively.

To understand creative thinking, we must first understand how we perceive and process information. Edward de Bono [4] proposes a theoretical model of the manner in which the brain accepts information and data at every moment and relies on a system of patterns for dealing with that information. Since the brain seeks to sort information into patterns, in some sense, it only sees what it wants to see. Any information that is seemingly incompatible with the existing system of patterns is handled by:

1. Discarding: Filtering the information out or ignoring it completely.

2. Forcing fitting: Using the best possible pattern, usually resulting in a misunderstanding of the validity or importance of the knowledge. 
3. Developing new patterns: Slowly creating a new set of patterns (usually based on existing patterns) to accommodate more of this new type of information These patterns for managing information have been called paradigms [4] frames of reference [9], pattern languages [1] or templates [18]. The brain has the ability to immediately select the appropriate pattern or template to match a given piece of information. For example, it has been calculated that there are ten to the power of ten to the power of fifty ( 1 followed by 500 zeroes) chess moves [7]. No grandmaster has ever memorized that many moves. Only certain sequences of moves are understood. Whenever a chess situation is analyzed, it is done by comparison with a suitable known sequence of moves. Obviously, there isn't usually a perfect sequence to be administered given the situation, but some sequences are stronger than others. The great chess layers are those that can recognize a situation and apply the "best" sequence of moves from their arsenal of chess templates. The same use of patterns applies to our ability to recognize individual people amongst billions of others.

If the brain works in patterns and avoids any random actions, it might be said that the brain is not creative at all! Creativity starts by applying a way of thinking that breaks down these existing patterns. Because creativity requires an unnatural way of thinking, creative thinking contradicts apparent paradigms and often seems illogical and unreasonable. De Bono calls this 'lateral thinking' and Koestler coined the term "bisociation" for it.

When we are thinking creatively, we are processing information in one template or frame of reference while applying knowledge from another template. One can think of these templates as intersecting planes. For example, a plane of engineering knowledge intersecting with a plane of artistic knowledge. The intersection is the design problem area. Lateral thinking is the unnatural act of leaping from one plane (engineering) to a different plane (fine art) to bring in seemingly unrelated and irrelevant information. The act of exposing the thought processes of the engineer to the thought processes of the artist results in creative thinking. By moving (however slightly or unknowingly) onto an unfamiliar plane of thinking, the comfortable patterns of thought are broken and new, creative patterns begin to form.

This is the true value of familiarization. The act of collecting stories, points of view and experiences from a wide variety of stakeholders forces the designer (student or professional) to think creatively, if only because they receive information that does not fit their accustomed patterns and they must develop a means for dealing with that new information.

As a final example, Koestler [9] claims that this is how humour works. When the joke teller drops the punch line, the audience automatically searches the particular template related to the punch line. Laughter will not result unless the audience finds a point on the given template that links it to a completely different template. Once the bisociation has been made between two seemingly unrelated templates, the audience reacts to the absurdity by laughing. For example, consider the question: What is the difference between a violin and a viola? The answer is: The viola burns longer. The knowledge template dealing with music and musical instruments contains information about the similarity in shape and sound between the two instruments, the high cost of stringed instruments, the role of classical music, etc. The last two words suddenly throw the audience into the absurd notion of burning valuable musical instruments.

\section{Overcoming Roadblocks to Creative Thinking}

Similar to the joke, creative thinking violates the operating nature of the brain by leaping from one knowledge template to another. Whetten and Cameron [17] refer to the lack of creative thinking as a resistance to shifting templates due to of "conceptual blocks" that prevent any bisociative or lateral thinking. The blocks are a result of factors that influence the development of knowledge templates. Hyman [6] lists several of these influences:

1. Perceptual: Understanding of the problem is confined to an existing template.

2. Cultural: Socially created templates that dictate what is normal.

3. Emotional: Past experiences involving deep feelings can create undesirable knowledge templates.

4. Intellectual: Not enough information contained on a template.

Creative problem solving requires that designers extract themselves from the influence of conceptual blocks. Engaging in discourse with a variety of people serves as a springboard from which students are able to access a variety of knowledge templates or "different ways of knowing" about the world and thus mitigate the influence of conceptual blocks. As engineering students begin to engage in familiarization, they realize that there are many ways to think about design and in fact, many ways to think about the world around them. They begin to acquire the ability to overcome conceptual blocks.

\section{Implementing Familiarization}

We use six basic tools in our course to create the environment for familiarization:

1. Design teams

2. Engineering Logbooks

3. A personal style survey (ie. Gregorc Style Delineator)

4. Real world design projects that have not been solved

5. Real world clients

6. Multi-disciplinary instructors

In the running of ENGG 251 (Engineering Design and Communication) students are divided into design teams. For a class of 600 , we form 150 four person 
teams. A number of methods have been employed to set the teams (departmental interests, self-selection, skill areas, project interest). Only the self-selection method has proven unsuccessful since friends tend to think similarly and resist any new information. All other methods involve forming teams made up of people with different interests and/or skills.

A significant part of the course grade is connected to the maintenance of a logbook for keeping track of meetings, ideas, drawings, calculations, research, contacts, agreements, etc. Without the logbook, the typical engineering student with his/her preference for factual and analytical detail will fail to document the familiarization information required for effective synthesis.

The personal style delineators such as Meyers-Briggs or Gregorc has a significant impact on the students as they realize (many for the first time) that their peers do not all think the same or have the same knowledge, skill and, more importantly, do not have the same preferences for thinking and working. They even have different grade expectations. Therefore, each design team is required to write a team contract to stipulate what constitutes adequate performance in the team and what the penalty for poor performance will be.

Real world design projects and real world clients force the students to seek new and broad-based information. They cannot, as is the common practice in engineering school, seek ready made answers from students who have already taken the course. In the absence of a well traveled solution path, creative thinking is the only option. In addition, once the students are removed from the familiar environment (textbook as source, instructor as expert) and once they realize they will be working with and reporting to potential employers, the creativity and quality of their work radically improves. However, it should be noted here that their vocal expression of discomfort and uncertainty also radically increases. A real world design class is a chaotic, often uncomfortable place.

Perhaps the most important tool for developing a creative environment is the presence of a multidisciplinary instructional team. Our team consists of two professional engineers, an artist in residence and a writer in residence. The team is continuously engaged in designing the course since, as a rule, we do not repeat projects from year to year and real world projects have a high degree of day to day instability. The instructors also provide an important source of familiarization modeling and information since their fields of expertise are diverse.

\section{Conclusion}

In order to solve the current problem of a shrinking resource pool of engineering designers/innovators, we recognize the need to reintegrate the human experience into the practice of design engineering. The development of the Design Trinity (Familiarization, Functionality,
Testing) and its use in a real design evironment has enabled our first year engineering design and communication class of 600 to develop creative solutions to real world, open-ended problems.

The concept of familiarization arises from the realization that an environment for nurturing design, innovation and creative problem solving must necessarily be a participatory, social environment focused on communicative action. Communicative action requires participants to engage in discourse, listen to the points of view of others and negotiate what counts as knowledge. Without communicative action, synthesis cannot take place. Without synthesis, we are chained to the limited potential of technical rationality.

Thus, in our view, engineering design instruction becomes more a matter of creating the necessary environment for familiarization (and therefore creative thinking) and less a matter of dictating correct design theory. Six years of experience in developing an approach to the teaching and learning of engineering design at the University of Calgary, allows us to say with confidence that the design trinity and in particular, the concept of familiarization is an effective approach to creative problem solving.

\section{References}

[1] Alexander, C. et al, A Pattern Language. Oxford University Press: New York, NY, 1977

[2] Baraniecki, Ernest. "Familiarization: An Approach to Multi-Disciplinary Design”, Master of Science Thesis, University of Calgary, 1999

[3] De Bono, E. Lateral Thinking: Creativity Step by

Step. Harper \& Row, New York, NY, 1970

[4] De Bono, E. Serious Creativity: Using the Power of Lateral Thinking to Create New Idea. Harper Collins: New York, NY, 1992

[5] Caswell, D., Johnston, C., Fauvel, O.R., Douglas, D., Eggermont, M. "Fundamentals of a First-Year Engineering Design and Communications Course: Familiarization, Functionality and Testing", Proceedings of the ASEE conference, June 2004

[6] Hui, Zou. "From Foucault's Concept of Discourse to Building as Comparison", Design Methods: Theories, Research, Education and Practice. 33 (4) (Dec. 1999), pp. 2909-2917

[6] Hyman, B. Fundamentals of Engineering Design, Prentice-Hall Inc.: Upper Saddle River, 1998

[7] Kasner, E., Newman, J.R. Mathematics and Imagination.. Tempus Books of Microsoft Press: Redmond WA, 1989

[8] Khisty, C.J., Leleur S. "Citizen Participation Through Communicative Action: Towards a New Framework and Synthesis", Journal of Advanced Transportation., 31(2) 1997, pp. 119-137

[9] Koestler, A., The Act of Creation, Pan Books Limited: Bungay,UK, 1964 
[10] Mansour, Y., "Researching Design: Conceptual Framework" Design Methods: Theories, Research, Education and Practice, 33(2) Dec. 1999 pp. 2825-2836

[11] Poincare, H. Mathematical Creation, Penguin, London, UK, 1924

[12] Reason, P., "Three Approaches to Participative Inquiry" Handbook of Qualitative Research, Eds. Norman K. Denzin and Yvonna S. Lincoln, Sage Publications, London, UK, 1994, pp. 324-339

[13] Rittel, H.W.J., "Impressions of Architecture 130: Notes and Observations of Prof. Horst W. J. Rittel's Classic Design Methods Course at Berkeley as taught circa 1969-1971" Design Methods: Theories, Research, Education and Practice, 29(1), 1996 to 32(4)

[14] Schneider, B.A., Caswell, D.J., "Building Community and Creating Knowledge in the Interdisciplinary Classroom", History of Intellectual Culture, in press.

[15] Snodgrass, A. "On Theorizing Architectural Education" Architectural Theory Review: Journal of the Department of Architecture, University of Sydney, 5(2) Nov. 2000, pp. 89-93

[16] Sternberg, E. "An Integrative Theory of Urban Design", Journal of the American Planning Association, 6(3) 2000, pp. 265-278

[17] Whetten, D. A., Cameron, K. S., Developing Management Skills, $2^{\text {nd }}$ ed,: Harper Collins, Inc: New York, NY 1991

[18] Caswell, D.J., "Bell Plates and Multi-Disciplinary Design", Master of Science Thesis, University of Calgary, 1992 